\title{
The Effect of Warm Gutta-Percha Techniques on Viability and Mineralized Tissue Associated Gene's Transcripts of Human Periodontal-Ligament Mesenchymal Stem-Cells
}

\section{Nazife Tuğba Azmaz ${ }^{1}$, Serife Buket Bozkurt ${ }^{2}$, Sema Sezgin Hakki ${ }^{3}$ and Sema Belli* ${ }^{4 *}$}

${ }^{1}$ Specialist Endodontist, Meram Research and Training Hospital, Konya, Turkey

${ }^{2}$ Niğde Ömer Halisdemir University, Faculty of Medicine, Department of Medical

Biochemistry,Nigde, Turkey

${ }^{3}$ Full-Time Professor in Department of Periodontology, Selcuk University, Konya,

Turkey

${ }^{4}$ Full-Time Professor in Department of Endodontics, Selcuk University, Konya, Turkey

*Corresponding Author: Sema Belli, Full-Time Professor in Department of Endodon-
Received: March 20, 2021

Published: May 05, 2021

(C) All rights are reserved by Sema Belli., et al.

\section{Abstract}

Aim: The purpose of the this study was to assess the effect of continuous wave of condensation (CWCT) and thermoplastic guttapercha injection (TGI) techniques on the viability and mRNA expressions of mineralized tissue-associated proteins of human periodontal-ligament mesenchymal stem-cells (hPDL-MSCs).

Methods: hPDL-MSCs were isolated from premolar-teeth. Roots of human premolar-teeth were placed vertically to the cell-culture dishes. Six groups were designed as follows: control 1 (without teeth, C1); control 2 (with teeth C2); AH Plus group (AH); single-cone obturation group (SC); CWCT and TGI. The viability of the hPDL-MSCs was analyzed by 3-[4,5-dimethylthiazol-2-yl]-2,5-diphenyl tetrazolium bromide at $24 \mathrm{~h}$ and $96 \mathrm{~h}$. RNA was isolated from the hPDL-MSCs at $24 \mathrm{hrs}$ and cDNA synthesis was performed. The mRNA expression of mineralized tissue-markers including bone sialoprotein (BSP), osteocalcin (OCN), runt-related transcription factor-2 (Runx2), type I collagen (COL I), alkaline phosphatase (ALP), were evaluated by quantitative real time polymerase chain reaction (qRT-PCR).

Results: Reduced cell viability was observed in all groups except the controls. When SC and CWCT and TGI groups were compared, it was observed that heat had a significant negative effect on cell viability $(\mathrm{p}<0.05)$. Reduction in the mRNA expressions of BSP, OCN, and ALP were observed at the test groups and this negative effect was higher in the heat treated groups $(p<0.05)$.

Conclusion: Warm gutta-percha techniques reduced mRNA expressions of mineralized tissue-associated proteins which are critical for the functions of PDL-MSCs during healing at the apical region after endodontic treatment.

Keywords: Associated Proteins; Mineralized Tissue; Periodontal Ligament; Mesenchymal Stem Cells; Warm Gutta-Percha Techniques

\section{Introduction}

The root canals should be filled with a homogeneous, inert, dimensionally stable and easily manipulated material which has plastic consistency that can take the internal shape of the root ca- nals [1]. Use of a thermoplastic core material in combination with an endodontic sealer which has the properties listed above is the most widely accepted approach by the endodontists [2]. Guttapercha (GP) is still the most popular core material used in canal 
filling $[3,4]$. No other materials can be considered as a possible replacement for GP in its various forms. Hence, GP can be considered as a gold standard material for obturation [5].

GP can be used in variety of ways to obturate root canals. The single-cone technique is much faster and easier to operate [6] and can provide satisfactory obturation of the root canal [7] thus this method has gained popularity. Warm GP obturation techniques produce 3-dimensional root canal obturations because thermoplasticized GP can fill better canal irregularities than solid GP points [8]. On the other hand, heat generated in the canal cavity with warm GP techniques can be transmitted to the periodontal tissues and alveolar bone through dentin, cementum, PDL and damage can be occur in the tissues by high heat transfer [9-11]. A temperature rise above $10^{\circ} \mathrm{C}$ of normal body temperature can cause irreversible damage of periodontal tissues [12-14]. The thermal stimulus received during thermo mechanical compaction of guttapercha was reported to sufficient to cause periodontal membrane trauma while this effect is rapidly dissipated in vivo [13].

Periodontal ligament is a unique tissue in the human body between two mineralized tissues and plays critical role during the function of the teeth i.e. suspension when the tooth exposed to the forces and remodeling/regeneration capacity during the wound healing or orthodontic treatment synthesizing required proteins, enzymes, cytokines and their inhibitors $[15,16]$. This specialized tissue made possible these critical functions with these MSCs differentiating cementoblasts, osteoblasts or fibroblasts $[17,18]$.

During endodontic treatment, PDL around the apical region is inevitably exposed by several endodontic materials or solutions. Therefore, the endodontic therapy should provide biocompatible environment for the cells in the PDL. However, both chemical compositions of the applied materials and/or temperature changes during the treatment may have negative effects on the cells vicinity of the apex [19-21]. Proliferation and the differentiation of PDLMSCs are critical biological events for the healing of apical lesion to obtain new cementum and new bone [22]. Mineralized tissuerelated genes (COL I, OCN, BSP, Runx2, ALP) play critical roles for the differentiation of human periodontal-ligament mesenchymal stem-cells (hPDL-MSCs) [23]. Negative effects on these mineralized tissue differentiation markers mean that wound healing around apical region of the tooth may not be satisfactory. In addition to chemical content of the root canal filling materials, the increase in temperature during the application procedures may have effects on the cells. In a previous study, the effects of temperature rise during the application of warm gutta-percha techniques on the mRNA expressions of heat-shock proteins (HSP) and mineralized tissue-associated proteins of the immortalized mouse cementoblasts (OCCM.30) were evaluated [24]. The results showed that heat-shock proteins and mineralized tissue-associated proteins of cementoblasts were reduced with warm gutta percha techniques.

Any additional negative effects of warm gutta-percha techniques on tissues in cellular level was reported while the only report was published by Azmaz., et al. (2020) in a previous study by evaluating cementoblasts behavior. Therefore, this issue seems still unclear. The effects of warm gutta-percha techniques on hPDL-MSCs which are critical for apical healing was questioned in the present study. Thus, the purpose of this study was to assess the effect of continuous wave of condensation technique (CWCT) and thermoplastic gutta-percha injection (TGI) techniques on the mRNA expressions of hPDL-MSCs. The hypothesis was that temperature increase during the application of warm gutta-percha techniques negatively affects differentiation of the hPDL-MSCs.

\section{Materials and Methods}

This study was approved by Selcuk University Faculty of Dentistry Ethical Committee (2017/14) Konya, Turkey. Extracted human premolar-teeth with single and straight-canals were decoronated by using a thin diamond disc (Horico Dental, Berlin, Germany). Apical of the roots were removed in order to provide a flat surface contact in cell-culture dishes. In order to provide a perfect fit to cell culture dish, thus $10 \mathrm{~mm}$ long roots were obtained for cell-viability assay. For RNA expression assay, $14 \mathrm{~mm}$ long roots were used. Working lengths were determined with K-file (Dentsply, Maillefer, Ballaigues, Switzerland) and the root-canals were prepared up to the ProTaper Next X5 file in combination with $2 \mathrm{ml}$ 2.5\% sodium hypochlorite $(\mathrm{NaOCl})$ irrigation between each file. Sterilization of the roots was provided $\left(121^{\circ} \mathrm{C}\right.$ for $\left.20 \mathrm{~min}\right)$ and the roots were then fixed vertically to the cell-culture dishes (Figure 1). A total of 40 roots were used. For cell viability experiments, sample size was 3 for each group and for each time points $(n=30)$. Two roots were used in each group for RNA isolation tests $(n=10)$. 


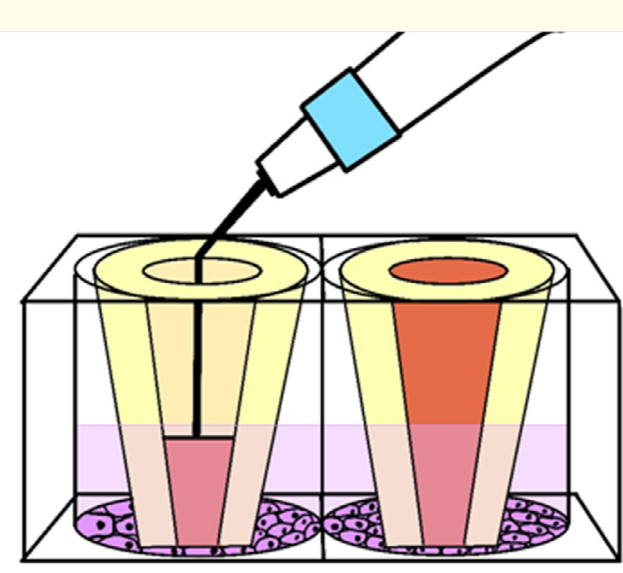

Figure 1: Schematic drawing of the experimental set-up.

The following test groups were created:

1. Control 1 (C1): Control cell group without root samples;

2. Control 2 (C2): Control group with sound roots;

3. Sealer group (AH): Group with root-canal sealer. The root canals in this group were dried with sterile paper-points and filled with AH Plus (Dentsply De Trey, Konstanz, Germany).

4. Single-cone group (SC): Group with gutta-percha and root-canal sealer the root-canals in this group were dried and filled with ProTaper Next X5 gutta-percha cones in combination with $\mathrm{AH}$ Plus using with single cone technique. Gutta-cut (VDW, Germany) was used to cut the coronal gutta-percha.

5. TGI group: After drying and filling the root canals with AH Plus, the gutta-percha cartridge was heated at $150^{\circ} \mathrm{C}$, the tip of the cannula was inserted into the canal and the canals were filled by using dental thermoplastic guttapercha injection technique.

6. CWCT group: The root-canals in this group were filled and prepared as Group 4. The unit of the Elements ${ }^{\mathrm{TM}}$ free Cordless Obturation System (SybronEndo) was set to $200^{\circ} \mathrm{C}$. In a pilot study, Azmaz., et al. (2020) measured the temperature rise at apical via thermocouples in a $20^{\circ} \mathrm{C}$ laboratory environment and in order to reach $38.7^{\circ} \mathrm{C}$ at the apical, the authors decided to keep the plugger within the canal for 90 seconds [24]. The laboratory conditions were similar to this previous study thus in the present study the plugger [.06 (Buchanan Heat Plugger) (Sybron Endo)] was inserted $3 \mathrm{~mm}$ above the apex and heat was applied for 90 seconds. The heat was re-applied and the plugger was quickly removed from the canals. Harmful effect of initial temperature rise at apical was targeted in this study thus temperature decrease while removing the plugger was disregarded at this moment. A hand instrument was then used to condense the gutta-percha. It was planned to remove the over or under-filled samples from the study therefore optimum care was paid during the obturation procedures. The lack of extrusion was confirmed. The remaining coronal portion of each tooth was then filled according to the manufacturer's instructions.

\section{Cell culture experiment}

Human periodontal ligament (hPDL) tissues were obtained from premolar teeth extracted for orthodontic reasons. Three donors who were systemically periodontally healthy $(12,15,18$ years old, 2 female, 1 male) were the volunteers. Written informed consent forms were obtained and the study was approved by the Ethics Committee of the Faculty of Dentistry, Selcuk University. Undifferentiated pdl-MSCs ( $n=3$, passage 3 ) were checked for antibodies against the human antigens (CD5, CD7, CD10, CD11b, CD13, CD14, CD15, CD19, CD29, CD33, CD34, CD44, CD45, CD71, CD73, CD90, CD105, CD106, CD117, CD146, CD166, HLA-ABC, and HLADR) using FACS Calibur (BD Biosciences, San Jose, CA, USA) and the results were analyzed for MSC specific markers utilizing software CellQuest (BD Biosciences).

Mesenchymal stem cells characteristics of hPDL were described International Society for Cellular Therapy [25]. Mesenchymal stem cell definition experiments including flow-cytometric analysis, immunofluorescence staining, telomerase activity and multilineage differentiation capacity of hPDL-MSCs were determined according to a previously published protocol [18].

\section{MTT assay}

The effect of warm gutta-percha techniques on cell-viability of hPDL-MSCs was measured using the 3- (4,5-dimethylthiazol2-yl)-2,5-diphenyltetrazolium bromide (MTT) assay. For this purpose, hPDL-MSCs were seeded in 96-well plate at a density of 10.000 cells/well for 24-hour and 96-hour experiments. After 24 hours of hPDL-MSCs attachment, the root specimens were careful- 
The Effect of Warm Gutta-Percha Techniques on Viability and Mineralized Tissue Associated Gene's Transcripts of Human Periodontal-Ligament Mesenchymal Stem-Cells

ly moved to 96-well plates, and root canals were clouded according to the manufacturer's protocol in laminar flow cabinet. After two different waiting periods (24 - 96 hours), in order to evaluate hPDL-MSCs cell-viability, $200 \mu \mathrm{l}$ MTT $(0.55 \mathrm{mg} / \mathrm{ml})$ was added to the culture medium and incubated at $37^{\circ} \mathrm{C}$ under $5 \% \mathrm{CO}_{2}$ for $4 \mathrm{~h}$ then dripped with $200 \mu \mathrm{l}$ of DMSO. The absorptions were read with ELISA reader at $540 \mathrm{~nm}(\mu$ Quant Bio-Tek Instruments Inc, Winooski, USA).

\section{Total RNA Isolation and complementary DNA synthesis}

To determine the effect of continuous wave of condensation (CWCT) and thermoplastic gutta-percha injection (TGI) techniques on mRNA expressions of mineralized tissue-associated proteins of hPDL-MSCs were incubated in $60 \mathrm{~mm}$ cell culture dishes at $25 \times$ $10^{3}$ cells $/ \mathrm{cm}^{2}$ for $24 \mathrm{~h}$. Then, root specimens $(\mathrm{n}=2)$ were placed in $60 \mathrm{~mm}$ cell culture dishes in the insert tool for heat application. Following this step, total RNAs isolated from hPDL-MSCs using a monophasic solution of phenol and guanidine isothiocyanate (Invitrogen, Camarillo, CA, USA) at $24 \mathrm{~h}$ after exposure to heat.

Complementary DNA (cDNA) synthesis and quantitative reverse transcription-polymerase chain reaction (RT-PCR)

The RNA concentrations were measured by nanodrop and single-stranded complementary DNA (cDNA) was performed from 1 $\mu \mathrm{g}$ of total RNA using cDNA synthesis kit (RevertAid First Strand cDNA Synthesis Kit; Thermo Scientific, Waltham, MA, USA) as previously described (Bozkurt., et al. 2019). Real-time PCR experiment was performed using the Stratagene MX3000P System (Stratagene MX3000P, La Jolla, CA, USA) and SYBR Green QPCR Master Mix (Maxima SYBR Green qPCR Master Mix (2X); Thermo Scientific). The reaction mixture contained $1 \mu \mathrm{L}$ of cDNA template, $12.5 \mu \mathrm{L}$ of SYBR Green QPCR Master Mix, $0.5 \mu \mathrm{L}$ each of the forward and reverse primers $(10 \mathrm{mM})$, molecular grade water that was added to make up the final volume to $25 \mu \mathrm{L}$. Each reaction was performed in three replicate samples. Glyceraldehde-3-phosphate dehydrogenase (GAPDH) gene was used as the house keeping gene. Subsequently, the specificity of PCR amplifications were confirmed with the melting curve analysis of software associated with Stratagene MX3000P System. Relative gene expression levels were evaluated using the 2- $\Delta \Delta \mathrm{CT}$ method [26]. The primer sequences for mineralized tissue markers (BSP, OCN, Runx2), COL I, ALP) are listed in table 1.

\begin{tabular}{|c|c|c|}
\hline Primer & Forward & Reverse \\
\hline ALP & CATTTGCCCTGAAACTC & CACCCTTCCTCCCTGCTGTA \\
\hline BSP & GCCTGTGCTTTCTCAATG & TTCCTTCCTCTTCCTCCTC \\
\hline OCN & CATGAGAGCCCTCACA & AGAGCGACACCCTAGAC \\
\hline Runx2 & CTTCATTCGCCTCACAAAC & GTCACTGCGCTGAAGA \\
\hline COL I & TTTGTGGACCTCCGGCTC & AAGCAGAGCACTCGCCCT \\
\hline GAPDH & $\begin{array}{c}\text { ACCACAGTCCATGCCAT- } \\
\text { CAC }\end{array}$ & TCACCACCCTGTTGCTGTA \\
& \multicolumn{2}{|c}{} \\
\hline
\end{tabular}

Table 1: List of primers.

\section{Statistical analysis}

The cell viability assay (MTT) results were analyzed using a one-way analysis of variance (ANOVA) combined with Dunnett test and Tukey honestly significant difference test. The data are presented as mean $\pm \mathrm{SD}$. A value of $\mathrm{P}<0.05$ was considered statistically significant, and a value of $\mathrm{P}<0.01$ was considered statistically highly significant. RT-PCR results were normalized using the comparative $\mathrm{Ct}$ method and the normalized values were compared with one-way analysis of variance (ANOVA). The increase and decrease of the expression of target genes compared to GPADH were given over $95 \%$ confidence intervals and $\mathrm{p}<0.05$ was considered statistically significant.

\section{Results}

\section{MTT assay}

The cell-viability of heat applied hPDL-MSCs was determined by MTT at 24 and $96 \mathrm{~h}$. As shown in figure 2, cell viability was significantly reduced in all groups at the end of $24 \mathrm{hrs}$ when compared to control 1 group. No significant difference was found between the $\mathrm{AH}, \mathrm{SC}$ and TGI groups and C2 group which contain only the sound roots $(\mathrm{p}>0.05)$ while cell viability significantly reduced in CWCT group when compared all the other test groups $(\mathrm{p}<0.05)$. The cell viability reduced in all groups when compared to control groups at the end of 96 hours ( $p<0.05)$. CWCT group showed the least cell viability when compared to the others $(\mathrm{p}<0.05)$. 

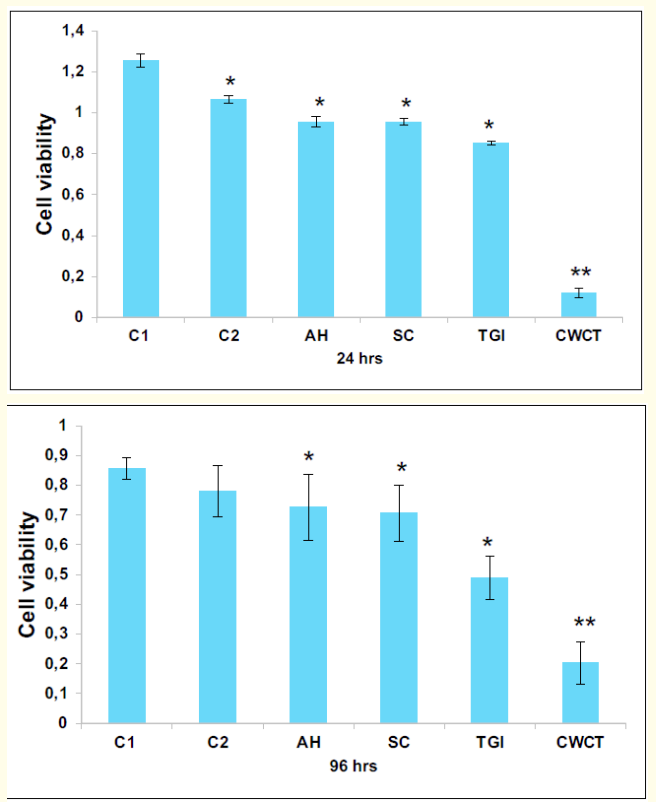

Figure 2: The viability of the hPDL-MSCs at $24 \mathrm{~h}$ and $96 \mathrm{hrs}$.

\section{Real-time PCR}

The results of RT-PCR indicated that mRNA expressions of BSP, OCN, COL-I, RunX2 and ALP were reduced in all groups including $\mathrm{C} 2$ when compared to $\mathrm{C} 1(\mathrm{p}<0.01)$ (Figure 3$)$. A significant difference was found between the test groups and C2 group in mRNA expressions of RunX2 ( $<<0.05)$.

When the obturation techniques were separately evaluated, BSP, OCN and ALP mRNA expressions were significantly reduced in warm gutta-percha technique groups (TGI and CWCT) when compared to single cone $(\mathrm{SC})$ technique $(\mathrm{p}<0.05)$. mRNA expressions of BSP was lower in CWCT group when compared to TGI and SC groups $(\mathrm{p}<0.001)$ (Figure 3). Both warm gutta-percha techniques reduced OCN mRNA expressions in hPDL-MSCs when compared to SC technique $(\mathrm{p}<0.01)$ while TGI technique showed the lowest ( $p$ $<0.001)$. CWCT technique reduced the mRNA expressions of ALP significantly more than SC and TGI techniques ( $\mathrm{p}<0.001)$. A significant difference also found among the TGI and SC groups $(\mathrm{p}<$ $0.001)$
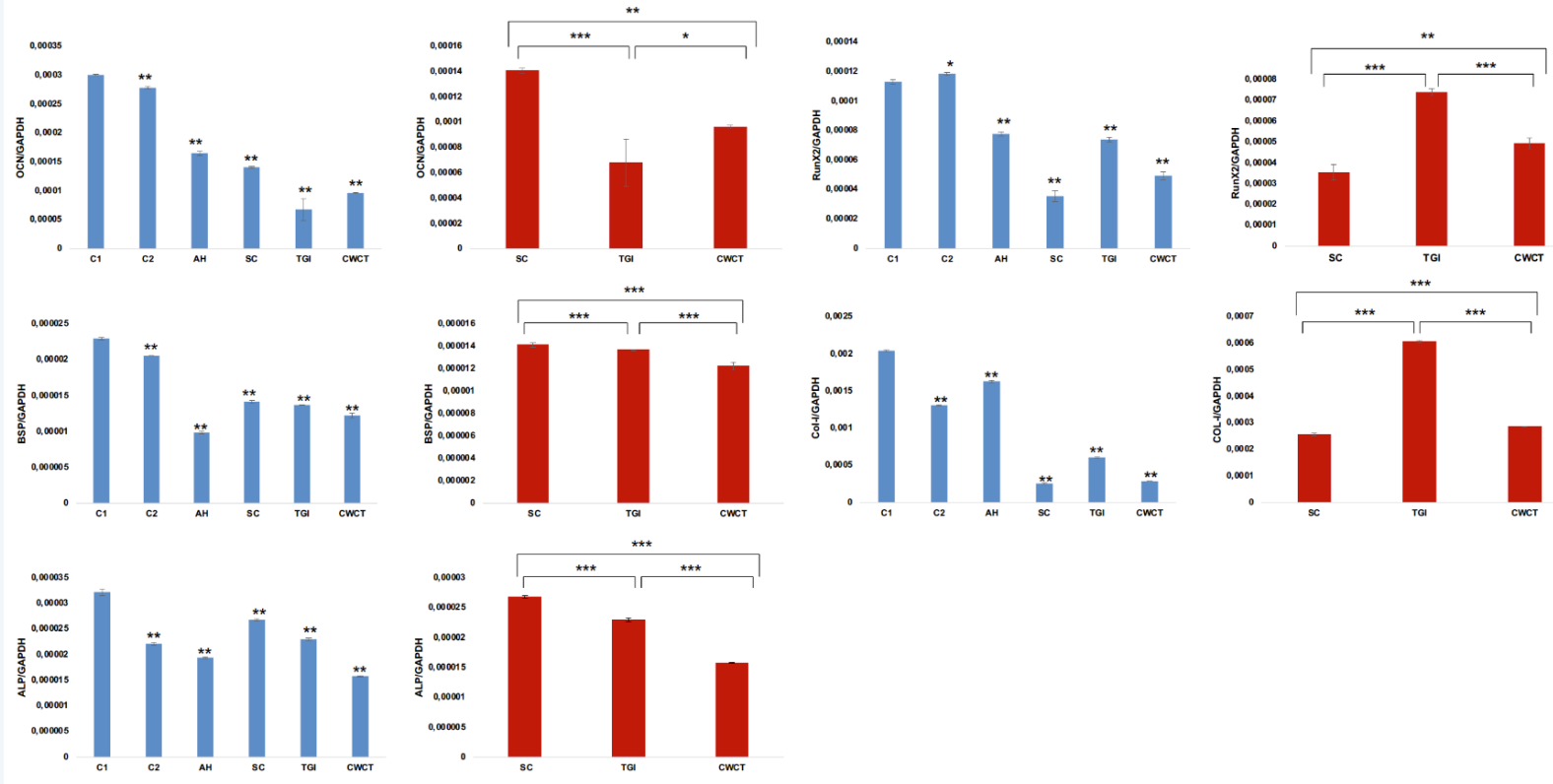

Figure 3: BSP, OCN, ALP, COL-1, RunX2 mRNA expressions of hPDL-MSCs $\left({ }^{*} \mathrm{p}<0.05\right.$; **p $\left.<0.01 ;{ }^{* *} \mathrm{p}<0.001\right)$. 
All groups had importantly reduced RunX2 expressions when compared to control groups ( $\mathrm{p}<0.01$ ) while decrease in COL-I mRNA expressions was not significantly different from Control 2 group (with sound roots) ( $\mathrm{p}>0.01$ ). Both CWCT and TGI groups increased RunX2 and COL-I mRNA expressions when compared to SC group ( $\mathrm{p}<0.01$ and $\mathrm{p}<0.001$ respectively). A significant difference also found between TGI and CWCT groups ( $p<0.001)$.

\section{Discussion}

The results of this study revealed that the temperature rise during the application of warm gutta-percha techniques reduced the cell viability and mRNA expressions of mineralized tissue-associated proteins which are critical for the functions of hPDL-MSCs thus the hypothesis of the study is accepted. MTT is a simple, rapid and easily repeatable method which is considered one of the most reliable test to evaluate the cytotoxicity of dental materials [27,28]. However, different methodologies or cell lines can affect the results [27] therefore, MTT analysis may not be sufficient alone to evaluate cell viability and should be supported by other methods [18,29]. Since, real time cell analyzing system cannot be employed due to the 3D methodological design of this study, MTT analysis was used. $\mathrm{AH}$ Plus was used as root-canal sealer and one group was created from the roots including only sealer in order to differentiate possible negative effects of temperature rise on the cells. The results showed that all the test conditions reduced the cell viability including the control group with sound roots (C2) at the end of 24 hours while at the end of 96 hours, cell viability was significantly lower than both control groups ( $\mathrm{p}<0.01)$.

Looking at BSP mRNA expressions, the greatest decrease was observed in the root canal filling paste group (Figure 3). While there was no significant difference between the single cone technique and the TGI group ( $\mathrm{p}>0.05$ ), BSP expression was significantly lower in CWCT group compared to SC group ( $p<0.001)$. Accordingly, the negative effect of root canal filling paste used in this study on hPDL-MKH is more significant than the effect of heat showing that a less cytotoxic root canal filling paste can be used safely with both warm gutta-percha techniques used in this study in terms of BSP expression. MTT cell viability test results also showed that the AH group significantly decreased the cell viability at 24 and $96 \mathrm{hrs}$ compared to the control 1 group. The expression levels of BSP, OCN, COL I, Runx2, ALP mRNA were decreased in the AH groups.
At both time points, CWCT group showed the lowest cell viability $(p<0.001)$. It has been reported that the heat generated during the application of warm gutta-percha techniques can be transmitted to the periodontal tissues and alveolar bone throughout the dentin and cement, and the tissues can be damaged [9-11,30]. Confirming the idea that dental root tissues are weak thermal conductors [11,31,32]. Gutmann., et al. (1987) reported no obvious periodontal damage after injecting warm gutta-percha (Obtura, $160^{\circ} \mathrm{C}$ ) into the root canals of a mongrel dog [32]. The authors also reported that the temperature changes on the outer surface of the bone in contact with roots were maximum $1.1^{\circ} \mathrm{C}$ in 60 seconds [32]. Romero., et al. (2000) reported maximum temperature rise as $1.75^{\circ} \mathrm{C}$ for upper canines and $2.0^{\circ} \mathrm{C}$ for the mesial roots of mandibular teeth when System B plugger was heated to $200^{\circ} \mathrm{C}$ for 10 seconds in $37^{\circ} \mathrm{C}$ environment temperature [33]. The temperatures on the root surface were found to be below the critical level with Thermafil, Soft Core and Obtura systems [34]. A sudden temperature decrease was also reported in the same study as soon as gutta-percha contacted the canal wall [34]. This temperature decrease was explained by the authors as a result circulation present in dentinal tubules and the periodontal ligament. In our study, extracted human teeth were used and the roots were sterilized at the beginning of the experiment. This experiment condition might have removed the fluid from the dentinal tubules and dryness might have resulted in more heat transmission when compared to the vital teeth. Furthermore, 90 seconds application duration which is not clinically relevant was used to reach $38,7^{\circ} \mathrm{C}$ at apex with CWCT system based on a previously published laboratory set up [24]. Increased effect of temperature on cell viability with CWCT system can be explained by the increased application period in the present study on the other hand, this result may be important in order not to ignore a possible side effect while taking advantage of this technique during the clinical procedures.

In biocompatibility studies, in addition to evaluating the viability of the cells, mineralized tissue-related genes (COL I, OCN, BSP, Runx2, ALP) are studied in mRNA levels in order to determine whether the cells maintain their functions and homeostasis of the periapical tissues. Type I collagen is the most important structure of collagen connective tissue and is an important protein in the extracellular matrix for maintaining tissue integrity. BSP and OCN are important markers that cause nucleation in the extracellular matrix in bone tissue and take the tissue towards mineralization while

Citation: Sema Belli., et al. "The Effect of Warm Gutta-Percha Techniques on Viability and Mineralized Tissue Associated Gene's Transcripts of Human Periodontal-Ligament Mesenchymal Stem-Cells". Acta Scientific Dental Sciences 5.6 (2021): 11-20. 
ALP is an important enzyme that converts organic phosphate into inorganic phosphate [35]. Runx2 is a critical transcription factor in the observation of bone formation $[35,36]$ and BSP is a non-collagen protein expressed by mineralized tissues such as bone, dentine, cementum and newly formed bone [17,37-39]. Mineralized tissue-related genes COL I, OCN, BSP, Runx2, ALP were reduced in all the test groups in the present study when compared to the control groups $(\mathrm{p}<0.05)$. According to the analyses which compare all the test groups, the sealer, gutta-percha in combination with sealer or temperature rise might be one of the factors which affect the genes in the test groups (Figure 3a). However, when the warm GP groups were compared only with SC group, it is clearly seen that COL I, OCN, BSP, Runx2, ALP were significantly reduced ( $<<0.01)$ except BSP (Figure $3 b$ ). Heating GP did not change the BSP expressions in TGI group ( $p>0.05)$. Among the tested mineralized tissuerelated genes, OCN was the only one affected from the temperature rise. OCN is extremely specific to mineralized tissues and the most plentifully expressed non-collagenous gene by osteoblasts [40] and claimed to play a role in early phases of mineralization and in regulation of crystal growth [41]. Osteoblasts are the primary cells responsible for alveolar bone formation and PDL cells have potential to differentiate to osteoblasts or cementoblasts [42]. It is an efficient way to enrich osteoblasts by actively inducing the osteogenic differentiation of PDL cells [43]. Since OCN is an important marker of new bone formation [44], up regulation of OCN means that the PDL cells are induced to differentiate into cells that exhibit characteristics of mature osteoblasts. In previous studies, upregulation of OCN was attributed to the expression of Runx2 $[44,45]$ and it was confirmed by Liu., et al. (2015) that increase of Runx2 directly increase of OCN [42]. In this study expressions of both Runx2 and OCN were down regulated. However, this decrease was specific for OCN in the warm gutta-percha applied groups.

Shui and Scutt (2001) investigated the effect of temperature on human bone marrow-derived stromal cells (BMSCs) and the human osteoblast-like, osteosarcoma-derived MG-63 cells in culture conditions [46]. In their study, mild heat shock ( $1 \mathrm{~h}$ at $39-41^{\circ} \mathrm{C}$ ) induced proliferation, alkaline phosphatase activity and mineralization in human bone marrow stromal cells [46]. In contrast to these findings, our results demonstrated that $38.7^{\circ} \mathrm{C}$ decreased cell viability and OCN mRNA expressions which is critical for osteoblastic differentiation. The reason of the difference can be explained as follows: in our experimental design, heat application period is short, the temperature and cell types used. By using warm guttapercha techniques, the clinician may cause restrain of stimulation of osteoblast at apical area thus negatively affect the apical healing process. At this point, the clinician should make a decision about the obturation procedure according to the clinical situation of the tooth. If bone formation and simulation of the osteoblasts at apical area is much more important than a perfect obturation, then the negative effects of lack of optimal obturation might be ignored.

In a previous study, Azmaz., et al. (2020) used similar method to evaluate the effect of warm GP techniques on mineralized tissueassociated proteins of cementoblasts [24]. The authors prepared a pilot study at the beginning of the experiment in order to simulate the temperature of oral environment. In our study, we followed the same experimental method. In the mentioned study above, also it was reported that warm gutta-percha techniques reduced mRNA expressions of mineralized tissue-associated proteins. Mineralized tissue-associated proteins have active roles during regeneration and the maturation phase and they are critical for the functions of PDL-MSCs especially for apical region healing after root canal treatment.

The experimental model used in the present study has limitations regarding homogeneity of heat and plating of 2D cell, Three-D culture studies might be provide more ideal experimental conditions however using 3D procedures have some disadvantages such as difficulty of the procedures.

The application of the technique was also did not completely mimic the clinical conditions. In order to evaluate the real effect of temperature rise on hPDL cells, the samples could be inserted to the cell dishes horizontally. On the other hand, it would not be possible to create a flat contact because of the concavity of the outer surfaces of the roots. Therefore, we decided to follow a recently published protocol and prepared flat surfaces by cutting the apical of the roots [24].

As we explain in our previous study, experimental methodology of the present study may not be well-simulated for clinical conditions and might have weakness for conclusion. However, there is no other option to test the change of apical temperature on the cells. Considering the cells which contribute healing around the apex, 
osteoblasts or bone marrow mesenchymal stem cells also could be further analyzed. Animal studies would better explain the real effects of heat. This in vitro study provides basic knowledge the molecular level effects of heat increase until animal studies performed and confirmed or not these in vitro findings.

\section{Conclusion}

Several advantages of warm gutta-percha techniques have been reported in the literature. This study showed that heat may reduce cell viability of PDL-MSCs and OCN mRNA expressions. Considering the critical role of PDL-MSCs on apical healing, differentiation potentials to the mineralize tissue forming cells; osteoblasts and cementoblasts, the negative effects of warm gutta percha techniques on the cell viability should be taken to account during heat assisted endodontic clinical applications.

\section{Bibliography}

1. LLI Grossman., et al. "Endodontic practice". Lea and Febiger (1988).

2. P Dummer. "Comparison of undergraduate endodontic teaching programmes in the United Kingdom and in some dental schools in Europe and the United States". International Endodontic Journal 24.4 (1991): 169-177.

3. L Spångberg. "Endodontic treatment of teeth without apical periodontitis". Essential Endodontics. Blackwell, London (1998): 211-241.

4. J Marciano and PM Michailesco. "Dental gutta-percha: chemical composition, X-ray identification, enthalpic studies, and clinical implications". Journal of Endodontics 15.4 (1989): 149153.

5. V Vishwanath and HM Rao. "Gutta-percha in endodontics-A comprehensive review of material science". Journal of Conservative Dentistry JCD 22.3 (2019): 216.

6. G Hommez., et al. "Endodontic treatment performed by Flemish dentists. Part 2. Canal filling and decision making for referrals and treatment of apical periodontitis". International Endodontic Journal 36.5 (2003): 344-351.
7. R Krug., et al. "Technical quality of a matching-taper singlecone filling technique following rotary instrumentation compared with lateral compaction after manual preparation: a retrospective study". Clinical Oral Investigations 21.2 (2017): 643-652.

8. H Schilder. "Filling root canals in three dimensions". Journal of Endodontics 32.4 (2006): 281-290.

9. RA Barkhordar., et al. "Evaluation of temperature rise on the outer surface of teeth during root canal obturation techniques". Quintessence International 21.7 (1990): 585-588.

10. JJ Jurcak., et al. "In vitro intracanal temperatures produced during warm lateral condensation of gutta-percha". Journal of Endodontics 18.1 (1992): 1-3.

11. $\mathrm{R}$ Weller and K Koch. "In vitro radicular temperatures produced by injectable thermoplasticized gutta percha". International Endodontic Journal 28.2 (1995): 86-90.as

12. A Eriksson and T Albrektsson. "Temperature threshold levels for heat-induced bone tissue injury: a vital-microscopic study in the rabbit". Journal of Prosthetic Dentistry 50.1 (1983): 101107.

13. E Saunders. "In vivo findings associated with heat generation during thermomechanical compactionof gutta-percha. Part II. Histological response to temperature elevation on the external surface of the root". International Endodontic Journal 23.5 (1990): 268-274.

14. FS Lee., et al. "A comparison of root surface temperatures using different obturation heat sources". Journal of Endodontics 24.9 (1998): 617-620.

15. O Trubiani., et al. "Periodontal ligament stem cells: current knowledge and future perspectives". Stem Cells and Development 28.15 (2019): 995-1003.

16. HJ Kim., et al. "Cytotoxicity and genotoxicity of newly developed calcium phosphate-based root canal sealers". Korean Medical Journal Information 31.1 (2006): 36-49. 
17. SS Hakki., et al. "Effects of mineral trioxide aggregate on cell survival, gene expression associated with mineralized tissues, and biomineralization of cementoblasts". Journal of Endodontics 35.4 (2009): 513-519.

18. SS Hakki., et al. "Comparison of mesenchymal stem cells isolated from pulp and periodontal ligament". Journal of Periodontology 86.2 (2015): 283-291.

19. E Saunders and W Saunders. "The heat generated on the external root surface during post space preparation". International Endodontic Journal 22.4 (1989): 169-173.

20. C Hauman and R Love. "Biocompatibility of dental materials used in contemporary endodontic therapy: a review. Part 1. Intracanal drugs and substances". International Endodontic Journal 36.2 (2003): 75-85.

21. G Botton., et al. "Toxicity of irrigating solutions and pharmacological associations used in pulpectomy of primary teeth". International Endodontic Journal 49.8 (2016): 746-754.

22. R Shinagawa-Ohama., et al. "Heterogeneous human periodontal ligament-committed progenitor and stem cell populations exhibit a unique cementogenic property under in vitro and in vivo conditions". Stem Cells and Development 26.9 (2017): 632645.

23. SS Hakki., et al. "Osteogenic differentiation of MC3T3-E1 cells on different titanium surfaces". Biomedical Materials 7.4 (2012): 045006.

24. NT Azmaz., et al. "Warm Gutta-Percha Techniques Regulate Cell Viability, Heat Shock, and Mineralized Tissue-associated Proteins of Cementoblasts". Journal of Endodontics 46.7 (2020): 957-963.

25. M Dominici., et al. "Minimal criteria for defining multipotent mesenchymal stromal cells. The International Society for Cellular Therapy position statement". Cytotherapy 8.4 (2006): 315-317.

26. KJ Livak and TD Schmittgen. "Analysis of relative gene expression data using real-time quantitative PCR and the 2- $\Delta \Delta \mathrm{CT}$ method". Methods 25.4 (2001): 402-408.
27. W Zhang., et al. "Evaluation of cytotoxicity of MTAD using the MTT-tetrazolium method". Journal of Endodontics 29.10 (2003): 654-657.

28. T Mosmann. "Rapid colorimetric assay for cellular growth and survival: application to proliferation and cytotoxicity assays". The Journal of Immunological Methods 65.1-2 (1983): 55-63.

29. SS Hakki., et al. "Bone morphogenetic protein -2, -6 , and -7 differently regulate osteogenic differentiation of human periodontal ligament stem cells". Journal of Biomedical Materials Research Part B: Applied 102.1 (2014): 119-130.

30. WA Castelli., et al. "Periodontium response to a root canal condensing device (Endotec)". Oral Surgery, Oral Medicine, Oral Pathology, and Oral Radiology 71.3 (1991): 333-337.

31. EM Hardie. "Further studies on heat generation during obturation techniques involving thermally softened gutta-percha". International Endodontic Journal 20.3 (1987): 122-127.

32. JL Gutmann., et al. "Evaluation of heat transfer during root canal obturation with thermoplasticized gutta-percha. Part II. In vivo response to heat levels generated". Journal of Endodontics 13.9 (1987): 441-448.

33. AD Romero., et al. "Heat transfer to the periodontal ligament during root obturation procedures using an in vitro model". Journal of Endodontics 26.2 (2000): 85-87.

34. SAT Al-Shimari and NE Al-Nuaimi. "Elevation in surface temperature of root canals obturated with different thermoplasticized gutta-percha obturation techniques-an in vitro study". Journal of Baghdad College of Dentistry 26.1 (2014): 67-70.

35. SS Hakki., et al. "Periodontal ligament fibroblast response to root perforations restored with different materials-a laboratory study". International Endodontic Journal 45.3 (2012): 240-248.

36. SS Hakki., et al. "The response of cementoblasts to calcium phosphate resin-based and calcium silicate-based commercial sealers". International Endodontic Journal 46.3 (2013): 242-252. 
37. YJ Choi., et al. "Enhanced osteogenesis by collagen-binding peptide from bone sialoprotein in vitro and in vivo". Journal of Biomedical Materials Research Part A 101.2 (2013): 547-554.

38. JA D’Errico., et al. "Expression of bone associated markers by tooth root lining cells, in situ and in vitro". Bone 20.2 (1997): 117-126.

39. SS Hakki., et al. "Bone sialoprotein gene transfer to periodontal ligament cells may not be sufficient to promote mineralization in vitro or in vivo". Journal of Periodontology 77.2 (2006): 167-173.

40. JB Lian., et al. "Osteocalcin gene promoter: unlocking the secrets for regulation of osteoblast growth and differentiation". Journal of Cellular Biochemistry 72.S30-31 (1998): 62-72.

41. AL Bronckers., et al. "Studies of osteocalcin function in dentin formation in rodent teeth". The European Journal of Oral Sciences 106.3 (1998): 795-807.

42. C Liu and J Sun. "Hydrolyzed tilapia fish collagen induces osteogenic differentiation of human periodontal ligament cells". Biomedical Materials 10.6 (2015): 065020.

43. A Pilloni., et al. "Migliaccio Analysis of human alveolar osteoblast behavior on a nano-hydroxyapatite substrate: an in vitro study". BMC Oral Health 14.1 (2014): 14-22.

44. A Neve., et al. "Osteocalcin: skeletal and extra-skeletal effects". Journal of Cellular Physiology 228.6 (2013): 1149-1153.

45. R Miron and Y Zhang. "Osteoinduction: a review of old concepts with new standards". Journal of Dental Research 91.8 (2012): 736-744.

46. C Shui and A Scutt. "Mild heat shock induces proliferation, alkaline phosphatase activity, and mineralization in human bone marrow stromal cells and Mg-63 cells in vitro". Journal of Bone and Mineral Research 16.4 (2001): 731-741.

\section{Assets from publication with us}

- Prompt Acknowledgement after receiving the article

- Thorough Double blinded peer review

- Rapid Publication

- Issue of Publication Certificate

- High visibility of your Published work

Website: www.actascientific.com/

Submit Article: www.actascientific.com/submission.php

Email us: editor@actascientific.com

Contact us: +919182824667 